\title{
Systematically Evaluating the Effectiveness of Quality Assurance Programmes in Leading to Improvements in Institutional Performance
}

Deirdre Lillis

Technological University Dublin, deirdre.lillis@tudublin.ie

Follow this and additional works at: https://arrow.tudublin.ie/scschcomart

Part of the Educational Assessment, Evaluation, and Research Commons

\section{Recommended Citation}

Lillis, D.:Systematically Evaluating the Effectiveness of Quality Assurance Programmes in Leading to Improvements in Institutional Performance. Quality in Higher Education. Volume 18, no 1, April 2012. doi:10.1080/13538322.2012.663549

This Article is brought to you for free and open access by the School of Computer Sciences at ARROW@TU Dublin. It has been accepted for inclusion in Articles by an authorized administrator of ARROW@TU Dublin. For more information, please contact arrow.admin@tudublin.ie, aisling.coyne@tudublin.ie,gerard.connolly@tudublin.ie.

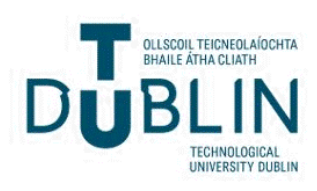




\title{
Systematically evaluating the effectiveness of quality assurance
}

\section{programmes in leading to improvements in institutional performance}

\author{
Deirdre Lillis
}

\begin{abstract}
Higher education institutions worldwide invest significant resources in their quality assurance systems however little empirical research exists which demonstrates their effectiveness (or otherwise). Methodological approaches for determining effectiveness are also underdeveloped. Self study with peer review is a widely used model for ensuring the quality of the core teaching, research and engagement activities of higher education institutions. This paper illustrates how an established social programme evaluation methodology can be used to determine its effectiveness in leading to improvements in institutional performance. The concept of effectiveness and the particular challenges posed by the higher education organisational culture are considered. An example of the systematic evaluation of three self study programmes is provided to illustrate the concept. It is concluded that social programme evaluation has significant potential in evaluating the effectiveness of quality assurance initiatives in higher education.
\end{abstract}

\section{Keywords}

Evaluation of effectiveness, social programme evaluation, quality assurance, higher education, self study with peer review

\section{Quality Assurance in Higher Education}

National quality assurance agencies, almost unheard of 20 years ago, are now in place in almost all OECD countries (OECD 2003). Stensaker notes that while there are a growing number of studies on quality assurance, there is a lack of research on the impact of quality assurance at institutional level (Stensaker 2007). He cites the methodological issues surrounding the assessment of the impact of quality assurance processes as a major challenge (Stensaker 2007). Harvey and Newton note that establishing definitive causal links and isolating their effects from other factors is a difficult task (Harvey and Newton 2004). Birnbaum states that there are 'few published examples in the academic sector of attempts to assess the institutional consequences of a management fad through data that provide evidence either of organizational outcomes or of the satisfaction of users' (Birnbaum 2000).

Evidence of the effectiveness of the core activities of higher education (teaching, research and engagement) is generally increasing however(Pascarella \& Terenzini 2005). It is important to note that this paper does not focus on the effectiveness of these core activities, rather the effectiveness (or otherwise) of the quality assurance instruments we use to assess them. These instruments are in widespread use by governments, higher education quality assurance agencies and internally within institutions. The question being addressed is to what extent we can trust these instruments.

Van Vught and Westerheijden found that the predominant model for quality improvement includes regular self-evaluations with external peer review by the higher 
education institute (Van Vught and Westerheijden 1995). Self study with peer review is often cited as being most suited to the "professional bureaucracy" type of organisation (Mintzberg 1983) as it gives ownership for quality to the Institution concerned. Kells notes that the external driver for self study programmes usually relates to accreditation status but that self study programmes often have additional internal aims (Kells 1992). As a form of quality assurance in higher education, self study programmes can take context into account, can straddle academic disciplines and are generally accepted by the academic community. Limitations of the model include its significant overhead, the length of time needed to complete a full cycle and the necessity of taking staff away from their core duties. It is therefore reasonable to ask what the return on this investment is, whether the model is fit for purpose and what substantive, additional improvements have resulted from the self study with peer review exercise. Massey highlights that public trust in higher education is being eroded (Massey 2003) and being able to ddemonstrate the reliability and validity of our quality assurance instruments to external stakeholders is essential for continued credibility.

El-Khawas notes that most policy research has focussed on institutional level effects even though the impact of self study with peer review programmes often depends on the reaction of departments and individuals (El-Khawas 1998). Sallinen et al. noted institutional impacts of self study with peer review which included improving transparency, communication, organisational learning, effectiveness and readiness for change (Sallinen et al. 1994). Henkel notes that self-study exercises could create 'new levels of understanding and mutual interest in a department' (Henkel 2004). Using a systematic evaluation methodology, Thorn found that self study with peer review led to an increased awareness of strategic planning, gave staff a forum for input to decision making and noted the failure in some instances to face up to weaknesses (Thorn 2003). Notwithstanding the above studies, and despite its widespread use in higher education, there is a significant lack of empirical research which demonstrates the effectiveness of self study with peer review.

\section{What do we mean by effectiveness?}

Social programme evaluation is widely used in the public and non-profit sector for undertaking research into the effectiveness and efficiency of programmes (Rossi et al 2003, Patton 2002). It has applications in domains where planned interventions are made to bring about improvements in people's lives (e.g. healthcare, social care, environment and public sectors). The social nature of programmes in these sectors share many similarities with quality assurance initiatives in higher education in their complexity and in the inherent difficulties of isolating the net effects of the programme from what would have happened anyway. Such evaluations are challenging, and it is not possible to give definitive answers, but we can still aim to give a credible estimate of the impact of a programme or intervention. While alternative evaluation approaches exist social programme evaluation was chosen for two reasons. Firstly it is accessible to a 'lay' reader whilst losing none of its rigour. Secondly its relatively widespread use in many different fields allows for comparability between studies.

We must first explore what we mean by effectiveness. The classic interpretation is that an effective programme is one which meets its stated goals and objectives. This leads to a rational, 'goals-oriented' evaluation approach (Vedung 1997). Problems 
can occur when goals are poorly articulated or not prioritised and it is possible that unanticipated side effect, both good and bad, are ignored. A broader concept of effectiveness is therefore required which also allows for improvements arising from programmes over and above what was intended or stated in the goals and objectives. This is termed 'prescriptive valuing' and leads to a 'goals-free' approach (Van der Knaap 1995). To give a rounded and credible estimate of the impact of a programme, effectiveness can be defined as (i) a programme must meet its stated goals and objectives and (ii) it may lead to additional (possibly unintended) improvements.

\section{Going beyond subjective opinion}

A reality-oriented post-positivist standpoint underpins this approach where results can be viewed in terms of probable causal effects and in which the reader has discretion to draw his/her own conclusions on the basis of the evidence presented. The goal is to minimise subjectivity and provide objective evidence of actual programme impact. The fundamental hypothesis tested is that 'the programme is effective in leading to improvements in performance'. Birnbaum noted that the private sector typically seeks empirical data to evaluate major management innovations whereas the higher education sector relies primarily on subjective judgment (Birnbaum 2000). Social programme evaluation seeks to find empirical evidence of effectiveness beyond the views of those involved in the programme. In social programme evaluation, the "judgments of experts, programme administrators and participants" who are asked to make "assessments of how the programme has affected them" are used sparingly and with caution (Rossi et al. 2003). The main concern is when such judgements are used definitively in isolation from other sources of data such as the document record of the institution. This emphasis on objectivity and triangulation of data sources has the potential to strengthen many studies on quality assurance in higher education. This in turn goes some way to addressing stakeholder perceptions of credibility.

\section{How do we evaluate the impact of a programme?}

Using a social programme evaluation approach, a programme is systematically evaluated using a four step process as follows (Rossi et al 2003):

- Assessment of the need for the programme

- Assessment of the process design

- Assessment of the impact of the programme

- Separating net from gross outcomes

\section{Assessment of need for the programme}

There is always a danger in any organisation that things are done the way we have always done them, blindly following convention without critical questioning of the need to do something. Rossi et al. note that evaluation of established programmes rarely focuses on the underlying conceptualisation as stakeholders are often reluctant to question tradition unless prompted to by exceptional circumstances (Rossi et al. 2003). Self study with peer review is a widely accepted method of quality assurance in higher education. Without empirical evidence to support its effectiveness, an assessment of the need for the self study programmes is considered important. Such an assessment clarifies the goals of the programme and considers alternative approaches. This questioning is required at all levels within the sectors, both within institutions and within the agencies that require institutions to undertake regular self study programmes. 


\section{Assessment of process design}

The design of a programme is important for two reasons. Firstly a programme may be badly designed, making it unfit for purpose and unable to achieve the intended outcomes (e.g. a template for a self evaluation report may not contain the appropriate headings). Secondly, it is possible that a well designed programme may be badly implemented (e.g. inadequate attention is paid to the selection of panel members with appropriate expertise, leading to inappropriate recommendations).

An assessment of process design also determines the extent to which the programme theory 'as-intended' was actually implemented. It is difficult to accurately assess the impact of programmes which have been partially or incorrectly implemented. For the self study with peer review the process assessment concentrates on the main activities as follows (i) internal self-evaluation of activities (ii) self study report (iii) peer review process and (iv) implementation of peer review recommendations and other improvements identified.

Patton notes that evaluations place varying degrees of emphasis on programme process evaluation (Patton 2002). Peer review panels often explore the process undertaken for internal self study in as much detail as the actual outcomes, as an indication of how valid the conclusions are. Undertaking a process evaluation also increases the generalisability of the research by providing a documented frame of reference for future evaluations. It also helps to distinguish between 'espoused theory' (what we would like to think happened) from the 'theory-in-action' (what actually happened) (Patton 2002).

\section{Assessment of the impact of the programme}

The purpose of clarifying programme impact theory is to determine in what way do programme activities effect changes. It is generally illustrated in a logic diagram (Figure 1) and is developed from the perspective of capturing the programme 'asintended'. Detailed process descriptions can be reconstructed and fully documented from the document record or from interviews with participants. Impact theory is based on the contention that outcomes which are a direct result of the programme (proximal outcomes) must be evaluated if longer term outcomes (distal outcomes) are to lead to improvements (Rossi et al. 2003). In other words the attainment of the overall goal of the programme is dependent on the attainment of intermediate outcomes such as the implementation of improvements identified by the internal team or by the expert panel. By way of example updates to course syllabi (a proximal outcome) lead to improvements in the relevance and quality of the course (a more distal outcome). While some of the richness of the programme may be lost in this approach, it is necessary to break down its complexity into a model which lends itself toward measurement.

As discussed earlier, to be considered effective programmes must meet their goals and objectives, requiring a 'goals-based' impact assessment. There is also provision for programmes leading to other (possibly unintended) improvements, requiring a goals-free' impact assessment.

\section{Goals-based impact assessment}

The classic 'goals-based' impact assessment is used to evaluate the extent to which programmes meet their stated goals and objectives. Rossi et al. contend that the ideal impact assessment design, if somewhat unrealistic for complex social programmes, is an experimental design (Rossi et al. 2003). This assumes that programmes are stable processes with pre-determined outcomes which can be represented by independent 
variables in a quantifiable fashion and where relationships between variables can be portrayed statistically.

The complexity and relative instability of social programmes means that a full experimental design is not possible and that a quasi-experimental design must be used instead. A reflexive 'Time Series Analysis' design is the strongest of these approaches (Rossi et al. 2003). This captures the impact of the programmes at a number of points in time including (i) the period before the programme started (ii) a mid-way point and (iii) the period after the programme. For example in the case of the self study programmes the period before the self study began, the panel visit and one year after the panel visit could be used. The selection of these time points is context specific and needs due consideration, as these may have a bearing on the outcomes. At these time points, objective evidence of completion of programme objectives is sought from various sources (e.g. an acknowledgement by the external peer review panel or the proceedings of relevant fora in the institution such as the academic council, senior management team or governing body). These can be supplemented by interviewing informants when necessary but it is essential to use triangulated data sources to minimise the reliance on subjective opinion.

When the goals of a programme are complex a key question that arises is what percentage of the goal must be complete for the overall goal to be considered complete? For example, if $80 \%$ of the recommendations of the external peer review panel have been implemented, can it be said that the goal of the programme has been met? The threshold set for the 'percentage complete' is therefore a key consideration and the determination of this threshold is not a straightforward exercise. The views of programme stakeholders, the literature base available for comparative purposes and the specific context of the programme are all important factors.

The programme impact theory states that outcomes which are a direct result of the programme (proximal outcomes) must be evaluated if longer term outcomes (distal outcomes) are to lead to improvements i.e. the goals of the self study are dependent on the implementation of the improvements identified and the external peer review recommendations. The aim of the goals-based element of the impact assessment is therefore to provide a credible estimate of the impact of the programmes. It must be acknowledged that this is not the ideal approach, that the resulting estimates of programme impact are not definitive and that the potential of bias must be actively counteracted. The quasi-experimental approach is nevertheless a feasible approach to take.

\section{Goals-free impact assessment}

House argues that goals-free evaluations are very challenging to do (House 1991) and Scriven suggests that a goals-free evaluation should run in parallel with a goalsbased evaluation for maximum effect (Scriven 1972). This ensures that the dynamic nature of the programmes can be accommodated even with the complexity of a changing environment (Patton 2002). The aim is to capture improvements which may have resulted from the programme but which were not explicitly stated in the goals and objectives (Patton 2002). Although these improvements may not have been anticipated it does not mean that they are not important and they can have positive or negative impacts (Rossi et al. 2003). For example the self study programmes may have led to improvements in building shared vision amongst staff, enhancing the leadership capabilities of the management team or clarifying future direction etc. . None of these were explicitly stated but are arguably as important an outcome as the stated objectives of the programme. Rossi notes that the firsthand accounts of 
programme informants is a good source of information for these types of impacts (Rossi et al. 2003).

\section{Separating net from gross outcomes}

The difficulties of isolating the impacts of quality assurance programmes from other factors is highlighted in the literature (Harvey and Newton 2004). The social nature of the programmes, the complexity of the environment and the number and range of participants makes it almost impossible to make definitive or positivistic statements in relation to this. This is not unique to higher education and it is a common problem for most complex social programmes. Separating net from gross outcomes is the most problematic but most critical aspect of programme evaluation which entails identifying what happened as a result of the programme compared to what would have happened anyway. Rossi et al note that the estimation of true programme impact is the most demanding evaluation research task (Rossi et al. 2003). Results therefore must be presented in probable terms. In essence this attempts to answer the questions "what would have happened anyway?". For example it is almost certain that an Institute or Faculty would respond to changes in its environment in various ways, irrespective of ever undertaking a self study programme. Improvements which found their origin in the normal day to day activities of the institution must be systematically identified and tracked in the document record, and then separated from improvements which found their origin in the programmes. Through thorough document analysis, each issue that arises during the time series is tracked from when it first appeared in the document record to its eventual completion, retirement or abandonment.

\section{Particular challenges for higher education}

The ease by which programme goals can be measured and evaluated is a key concern. There is a strong argument in the higher education literature that it is impossible to define any single combination of performance indicators which appropriately measure performance (Kells 1990; Linke 1992). Higher education is not unique in this regard however as many social programmes face similar challenges.

It is much easier to accurately assess the impact of programme when a high percentage of its objectives are written in measurable terms. Poorly articulated goals such as "produce good quality research" are ambiguous and difficult to measure whereas "have 10 papers published in peer reviewed journals" is more easily evaluated.

In the wider public sector management literature, Pollitt and Bouckaert provide a mechanism by which the type of result from a programme can be categorised, on the basis of the extent to which the result is evaluable or measurable. Results are categorised as being operational, process, capacity or ideological. This is outlined in Table 1 with examples adapted for higher education. Operational results are typically expressed quantitatively and compared with some preset standard (e.g. this year's student intake compared to last year). Process results are expressed in terms of the effect of improving activities (e.g. increasing graduate throughput whilst maintaining the quantity and quality of the student intake might suggest that the teaching process has improved). Process results need to be coupled with quality and cost data however (e.g. academic standards may have dropped to ensure a constant throughput of graduates). Capacity level results are improvements in either structures or culture, leading to organisations that are more flexible, that have a higher capacity to learn and are more responsive. 
In a programme evaluation, this classification is used in broad terms to provide a global assessment of how evaluable the goals and objectives of the programme are. For example if a self study programme has only a small percentage of its objectives at operational or process level it will be difficult to glean meaningful insights into its impact. Further work may be necessary to translate goals written in capacity or ideological terms into more measurable goals which lend themselves to evaluation.

\section{The systematic evaluation of the effectiveness of three self study with peer review programmes}

This is a worked example to illustrate the application of the social programme evaluation methodology described in this paper. The institutional impacts of three self study programmes undertaken during an 8 year timeframe (1997-2006) in one Irish Institute of Technology are evaluated. The Institute was required to undertake quinquennial institutional and school (faculty-level) reviews which entailed comprehensive self studies with external peer review. The first self study programme was called "Programmatic Review" (PR1) and was essentially a School Review (including a review of all teaching and research courses). The second self study programme was called "Delegated Authority" (DA1) and was at institutional level for the purposes of gaining degree awarding authority. The third self study programme was a second programmatic review (PR2) in the same School five years later. The external peer review panels commended the thoroughness of all three self study programmes, indicating that they are likely to provide good examples and will provide an information rich case study. This meets the criteria of an "intensity case" a case which is not unusual but from which much can be learned (Patton 2002).

The study straddles an eight year time period and the main data sources used were Institute documents including the reports of the self study programmes, proceedings of the Governing Body, the Academic Council, the Senior Management Team, School boards and Course boards. Semi-structured interviews were conducted with $n=17$ key informants who had a major involvement with the programmes. These included all of the senior management team and approximately half of the Heads of academic departments and Central Services Managers.

\section{An assessment of the need for the self study with peer review programmes}

Although the driving force for all three programmes was ultimately to meet external requirements linked to the accreditation status of courses of study (Table 2), they were also seen as opportunities to progress internal objectives. Given the scope of the three programmes it is likely that meeting the external requirements would by default bring many internal improvements also. The goal of the Delegated Authority programme (DA1) was essentially to achieve self-awarding status following an Institute-wide review of all activities but four additional internal objectives were also set. These included the implementation of a strategic management and continuous improvement framework. The school level Programmatic Reviews had internal objectives also which related to specific objectives from the Institute's strategic plan for implementation in the School (including modularisation of courses and the development of flexible modes of delivery). In essence all three programmes were needed as they were required by the quality assurance system.

\section{Assessment of the self study with peer review process}

An assessment of process design was undertaken to determine the extent to which the programme theory 'as-intended' was actually implemented as it is difficult to assess the impact of programmes which have been partially or incorrectly 
implemented. In summary all components of all three self study programmes were completed largely 'as-intended' as evidenced by the documents associated with each phase (e.g. self study report, panel report, etc.).

\section{An assessment of the impact of the self study with peer review programmes}

The goals and objectives of the three self study programmes are outlined in Table 2. For example the goal of PR1 is to ensure "(a) quality improvements are made to programmes of higher education and training and $(b)$ programmes remain relevant to learner needs, including academic and labour market needs". A set of three time points for each of the programmes were set to capture progress before, during and after each programme. Evidence of completion of the goals and objectives was sought, using the document record primarily (e.g. minutes of meetings, progress reports etc). An element of subjective judgement is unavoidable in setting the threshold for 'percentage complete' and for this reason a number of possible threshold values are illustrated to allow the reader to draw his/her own conclusions. At the 50\% threshold value all objectives of all the self study programmes were met (Table 3 ). The only deviation is at the $66 \%$ threshold for PR1 and PR2 (noting the shorter timeframe for the improvements from PR2 to be implemented).

DA1 was in essence a summative evaluation in that it made a judgment as to whether the Institute met the criteria for Delegated Authority or not (Table 2). No specific recommendations for improvement were made by the external review panel. $75 \%$ of the peer review recommendations for PR1 were completed and 30\% for PR2 were implemented (the shorter timeframe of the impact assessment should be taken into account when interpreting the PR2 results). Almost all recommendations made to courses of study were implemented within a short time period after the review. Revisions to courses took effect for the next intake of students to the courses.

The programme impact theory states that the proximal outcomes for the self study programmes are the objectives of the self study including implementing the peer review panel recommendations. At the $50 \%$ threshold, DA1 met $100 \%$ of its objectives, PR1 met $84 \%$ and PR2 met $61 \%$ (noting the shorter timeframe for PR2) (Table 5). The author argues therefore that, in gross terms, the self studies were effective in leading to improvements.

Other improvements arising from the self study programs were identified by asking informants what positive and negative impacts the self study programmes had. Nearly half the informants $(n=7)$ began their answer by stating that they didn't see any negatives with the self study process. The positive impacts most frequently cited by informants included concepts such as : the overhead involved $(n=9)$, building commitment $(n=8)$, the opportunity to review activities $(n=6)$ and involve stakeholders $(\mathrm{n}=3)$. Informants were also asked "Can you think of an example of something which wouldn't have happened without the self study process?". As expected many informants stated that it was a difficult question to answer or took more time before answering the question. Notwithstanding this over two thirds of the informants $(n=13)$ could think of a specific example of something they felt would not have happened without the self study process. These included ideas for new course development $(n=4)$, documentation of quality assurance procedures $(n=3)$, prioritisation of research $(n=2)$ and cross-departmental teamworking $(n=2)$. Two informants that could not think of a specific example but still thought that certain things would not have happened without the self study process. One stated that without self study "everything just stagnates, there's no fresh thinking”. 


\section{Separating net from gross outcomes}

The outcomes of the three self study programmes were categorised as either originating within the programme or outside of it (Table 7). By way of example one objective of the programmatic review programme (PR1) was to "To review the development of the courses over the previous five years with particular regard to the achievement and improvement of quality". The PR1 process was the only mechanism within the quality assurance system by which substantive changes to courses of study could be made and therefore it can be clearly stated that this objective would not have been achieved without PR1. On the other hand one of the objectives of PR2 was to "To review the plans (of the School) for future development". At the time of PR2 each department had produced a strategic plan which was subject to an annual internal review and it is possible therefore this objective could have happened without PR2.

Extensive document analysis was used to trace the origin of the objectives and they were analysed from the perspective of whether they would have happened regardless of the programmes. In summary $75 \%$ of the completed objectives of DA1, 37\% of the completed objectives of PR1 and 30\% of the completed objectives of PR2 can be ascribed to the programme (i.e. they would not have happened without the programme). In summary, at least a third of the net improvements would not have happened without the programmes.

\section{Summary of programme evaluation}

It has been established that there was a need for the self study programmes and that the programmes were implemented largely 'as-intended'. The programmes were effective as the substantial majority of their objectives and peer review recommendations were completed. Informants also perceived the programmes to be effective. Three quarters of the outcomes of DA1 and approximately one third of the outcomes of PR1 and PR2 could be ascribed to the programme (net outcomes).

\section{Lessons learned and wider implications}

Much can be learned from the social programme evaluation literature and it has significant potential as a robust and versatile methodology for systematically evaluating the effectiveness of quality assurance processes in higher education. It has the added advantage of being accessible to a lay readership and providing a framework which enables comparisons to be made across numerous case studies and across sectors. Key questions remain for quality assurance agencies and higher education institutes. The most fundamental are whether tried and trusted processes for quality assurance are effective in leading to improvements and how do we know? The importance of context in higher education research means that institutions and agencies will often have to answer these questions for themselves. The overhead involved in self study programmes is significant and the question of whether the benefits outweigh the costs is an important one.

\section{References}

1. Birnbaum, R., 2000, 'The life cycle of academic management fads', Journal of Higher Education, 71, (1), 1-16.

2. Brennan, J. and Shah, T., 1997, 'Quality assessment, decision-making and institutional change', Tertiary Education \& Management, 3, (2), 157-164.

3. Davies, J., 2004, 'Cultural change in universities in the context of strategic and quality initiatives', European University Association. Geneva. 
4. El-Khawas, E., 1998, 'Strong state action but limited results: Perspectives on University resistance', European Journal of Education, 33, (3), 317-220.

5. El-Khawas, E., 2000, 'The impetus for organisational change : an exploration', Tertiary Education and Management, 6, 37-46.

6. Harvey, L. and Newton, J., 2004, 'Transforming quality evaluation', Quality in Higher Education, 10, (2), 149-165.

7. House, E. R., 1993, Professional evaluation. Sage Publications. London.

8. Kells, H. R., 1992, Self-regulation in higher education. Jessica Kingsley. London.

9. Linke, R. D., 1992, 'Some principles for the application of performance indicators in higher education, Higher Education Management, 4, (2), 194:203.

10. Patton, M. Q., 2002, Qualitative research \& evaluation methods. Sage Publications.

11. Rossi, P., Lipsey, M. and Freeman, H., 2003, Evaluation - A systematic approach. Sage Publications.

12. Sallinen, A., Konttinen, R. and Panhelainen, M., 1994, 'Interactive model of self evaluation quality assessment at the University of Jyvaskyla - A pilot study', Higher Education Management, 6, (3), 357:375.

13. Scriven, M., 1972, 'Prose and cons about Goal-Free evaluation', Evaluation Comment, 3, 1-7.

14. Stensaker, B., 2007, 'Impact of Quality Processes', EUA Case Studies 2007 Embedding quality culture in higher education.

15. Thorn, R., 2003, 'Self study in an Institute of Technology - an evaluation', EAIR Forum 2003 (European Association of Institutional Researchers). University of Limerick, Ireland. 2003

16. Valimaa, J., 1994, 'Academics on assessment and the peer review Finnish experience', Higher Education Management, 6, (3), 391:408.

17. Van Vught, F. and Westerheijden, D. F., 1995, 'Quality measurement and quality assurance in European higher education', In Quality Improvement in European Public Services, (Ed, Bouckaert, P.). Sage Publications, London.

18. Van der Knaap, P., 1995, 'Policy evaluation and learning : Feedback, enlightenment or argumentation', Evaluation, 1, (2), 189-216.

19. Vedung, E., 1997, 'Merit criteria and performance standards', In Public Policy and Program Evaluation, Transaction, New Brunswick, New Jersey, 247-264. 


\section{Appendices}

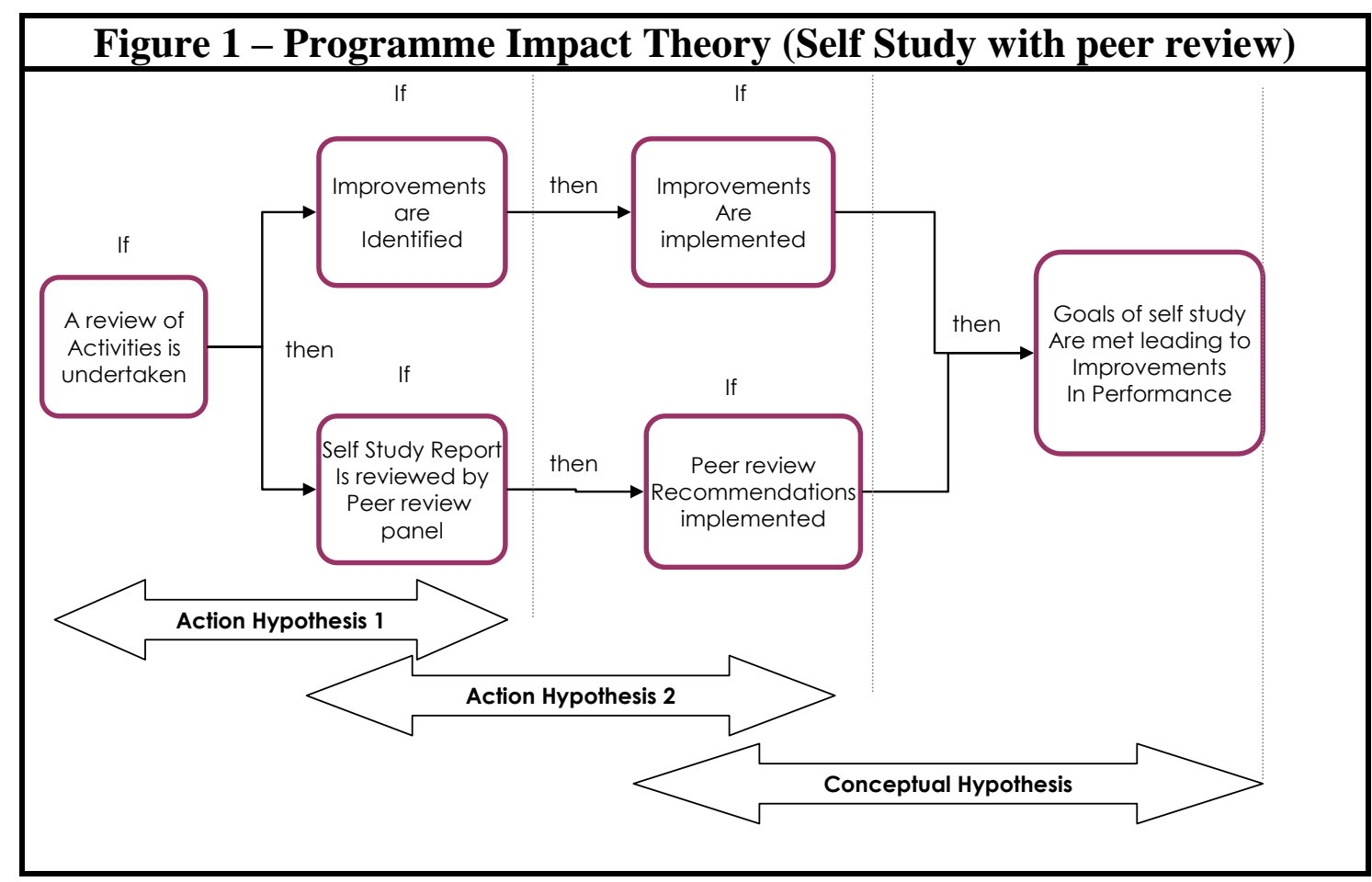

Table 1 - Taxonomy of Result Types (Pollitt and Bouckaert 2004)

\begin{tabular}{|l|l|l|}
\hline Result Type & Level & Description \\
\hline Operational & 1 & $\begin{array}{l}\text { Discrete and quantifiable results, efficiency measures. Examples include : objectives } \\
\text { with targets relating to student numbers; Retention rates, specific resources/facilities, } \\
\text { targeted marketing initiatives; Development of new courses; Implement specific } \\
\text { initiative (e.g schools visit programme) }\end{array}$ \\
\hline Process & 2 & $\begin{array}{l}\text { Improved management or decision making processes which are linked directly to actual } \\
\text { improvements. Examples include : developing links with stakeholders for specified } \\
\text { purpose (e.g. teacher training, assisting schools with specified projects); Introducing } \\
\text { change to organizational structure (e.g. new position created for specific purpose); } \\
\text { Developing and implementing a strategy/plan for a specific functional area (e.g. develop } \\
\text { marketing plan); Encourage/facilitate staff to participate in research/consultancy; } \\
\text { Ensuring equitable workload for students; Investigate new markets/new area ; Course } \\
\text { development strategy in new area) }\end{array}$ \\
\hline Capacity & 3 & $\begin{array}{l}\text { Systems level outcomes which enhance the capacity of the organisation. Examples } \\
\text { include continued development of some activity without specified outcomes (e.g. } \\
\text { Developing links \& partnerships, improving quality/overall student experience, } \\
\text { encouraging teaching excellence, encourage campus company startups). Change in } \\
\text { organisational culture (e.g. managing in more open and consistent manner, or more } \\
\text { effective and efficient manner); Development of centre of excellence; Contribute to } \\
\text { national policy etc. }\end{array}$ \\
\hline Ideological & 4 & $\begin{array}{l}\text { Movement of organisation toward desired or ideal state; intangible but desirable states } \\
\text { (e.g. total quality culture in all operations, foster an entrepreneurial ethos, enhance } \\
\text { standing as a contributor to regional development) }\end{array}$ \\
\hline
\end{tabular}




\begin{tabular}{|c|c|c|c|}
\hline Programme & $\begin{array}{c}\text { Delegated Authority Self Study } \\
\text { (DA1) }\end{array}$ & $\begin{array}{c}\text { Programmatic Review 2000/01 } \\
\text { (PR1) }\end{array}$ & Programmatic Review 2004/05 (PR2) \\
\hline Scope & $\begin{array}{l}\text { Comprehensive review of all operations in } \\
\text { the Institute to include governance, } \\
\text { management and planning processes; } \\
\text { quality assurance processes; educational } \\
\text { and training programmes; research } \\
\text { activities; support services and others; } \\
\text { conditions attached to Delegated Authority } \\
\text { \& Qualifications Act. }\end{array}$ & $\begin{array}{l}\text { School/Department activities including } \\
\text { quality assurance; performance indicators; } \\
\text { employment of graduates; national and } \\
\text { international transfers; courses of study } \\
\text { and syllabi; facilities; staff development; } \\
\text { links with stakeholders; research and } \\
\text { consultancy; delivery methodologies; adult } \\
\text { education. }\end{array}$ & $\begin{array}{l}\text { School/Department activities including quality } \\
\text { assurance; performance indicators; employment } \\
\text { of graduates; national and international transfers; } \\
\text { courses of study and syllabi; facilities; staff } \\
\text { development; links with stakeholders; research } \\
\text { and consultancy; delivery methodologies; adult } \\
\text { education. }\end{array}$ \\
\hline Goal & $\begin{array}{l}\text { The Qualifications Act } 1999 \text { provided the } \\
\text { legislative framework by which Institutes } \\
\text { could purpose Delegated Authority by } \\
\text { adhering to criteria established by the } \\
\text { Higher Education and Training Awards } \\
\text { Council. } \\
\text { The goal of DA1 was stated by the } \\
\text { Institute as to ensure "the Institute is } \\
\text { granted authority to make awards, at } \\
\text { particular levels, across all three } \\
\text { Schools". }\end{array}$ & $\begin{array}{l}\text { Stated by HETAC as ensuring } \\
\text { "(a) quality improvements are made to } \\
\text { programmes of higher education and } \\
\text { training and } \\
\text { (b) programmes remain relevant to } \\
\text { learner needs, including academic and } \\
\text { labour market needs". }\end{array}$ & $\begin{array}{l}\text { Stated by the Institutes Quality Assurance } \\
\text { procedure (A7) as ensuring that each } \\
\text { programme/suite of programmes } \\
\text { - contributes to the achieving of the } \\
\text { Institutes aims ... } \\
\text { - offers a valuable educational experience } \\
\text { to learners } \\
\text { - are benchmarked against similar } \\
\text { programmes ... } \\
\text { - takes cognisance of the NQF } \\
\text { - complies with all the requirements of the } \\
\text { approved external validating body } \\
\text {...are assessed in terms of the resources } \\
\text { required to deliver same. }\end{array}$ \\
\hline Objectives & $\begin{array}{l}\text { The objectives as set by the Institute were } \\
\text { 1. To review the effectiveness of the } \\
\text { work undertaken since 2000 in } \\
\text { preparation for Delegated Authority } \\
\text { and to internally assess our state of } \\
\text { readiness for same..... }\end{array}$ & $\begin{array}{l}\text { The objectives as set by HETAC were } \\
\text { 1. To review the development of the } \\
\text { courses over the previous five years } \\
\text { with particular regard to the } \\
\text { achievement and improvement of } \\
\text { quality }\end{array}$ & $\begin{array}{l}\text { PR2 retained the original four HETAC and five } \\
\text { additional objectives were set as part of the } \\
\text { Institute's own procedure:- } \\
\text { 1. to analyse the effectiveness and the } \\
\text { efficiency of each of the courses approved } \\
\text { 2. to evaluate the physical facilities provided by }\end{array}$ \\
\hline
\end{tabular}




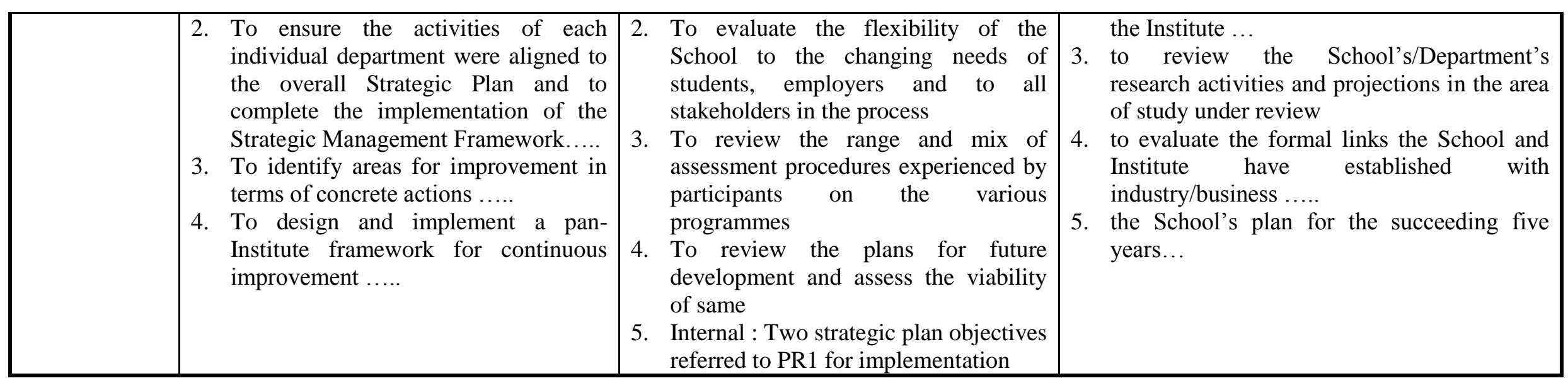

\begin{tabular}{|c|c|c|c|}
\hline \multicolumn{4}{|c|}{ Table 3 - Basis for impact assessment for DA1, PR1 and PR2 } \\
\hline & $\begin{array}{c}\text { DA1 } \\
\text { Delegated Authority Self Study 2003- } \\
2004\end{array}$ & $\begin{array}{c}\text { PR1 } \\
\text { School of Science and Computing } \\
\text { Programmatic Review } 2001\end{array}$ & $\begin{array}{c}\text { PR2 } \\
\text { School of Science and Computing } \\
\text { Programmatic Review } 2005\end{array}$ \\
\hline $\begin{array}{l}\text { Rationale } \\
\text { behind time } \\
\text { series selection }\end{array}$ & $\begin{array}{l}\text { May } 2005 \text { was chosen as the } \\
\text { Programmatic Reviews in the School of } \\
\text { Science and School of Engineering } \\
\text { provided an opportunity to review } \\
\text { progress on DA1. } \\
\text { June } 2006 \text { was chosen as the last available }\end{array}$ & $\begin{array}{l}\text { March } 2003 \text { was chosen as progress was } \\
\text { reviewed as part of the self study } \\
\text { undertaken as part of the Delegated } \\
\text { Authority process. } \\
\text { May } 2005 \text { was chosen as the second } \\
\text { Programmatic Review Process in the }\end{array}$ & $\begin{array}{l}\text { January } 2006 \text { was chosen as the School of } \\
\text { Science management team reviewed the } \\
\text { programmatic review recommendations } \\
\text { following approval of the report at the Academic } \\
\text { Council in November 2005. The plan for } \\
\text { implementing the recommendations was }\end{array}$ \\
\hline
\end{tabular}




\begin{tabular}{|c|c|c|c|}
\hline & $\begin{array}{l}\text { time point before the submission of this } \\
\text { thesis. }\end{array}$ & School of Science was completed then. & $\begin{array}{l}\text { presented to the School of Science School Board } \\
\text { in January } 2006 \text {. June } 2006 \text { was chosen as the } \\
\text { last available time point before the submission } \\
\text { of this thesis. }\end{array}$ \\
\hline Data Source & $\begin{array}{l}\text { Programmatic Review reports: School } \\
\text { of Science \& Computing and School of } \\
\text { Engineering \& Construction Studies } \\
\text { Programmatic Review self study reports. } \\
\text { Reports of the external peer review panels } \\
\text { for these programs. } \\
\text { Log of Issues : evidence of progress on } \\
\text { objectives and strategies was sought in the } \\
\text { document record. }\end{array}$ & $\begin{array}{l}\text { DA self study reports: Departments } \\
\text { progress reports for DA self study reports } \\
\text { and reports of the internal and external } \\
\text { peer review panels. } \\
\text { Programmatic Review self study } \\
\text { report: School self study report on } \\
\text { strategic plans for Programmatic Review } \\
\text { in } 2005 \text { and reports of the internal and } \\
\text { external peer review panels. } \\
\text { Log of Issues : evidence of progress on } \\
\text { objectives and strategies was sought in the } \\
\text { document record. }\end{array}$ & $\begin{array}{l}\text { School board presentation : January } 2006- \\
\text { update on status of programmatic review } \\
\text { recommendations made to School of Science } \\
\text { School board by Head of School. Minutes of } \\
\text { meeting of school of science management team } \\
\text { where action on programmatic review } \\
\text { recommendations was decided. } \\
\text { Programmatic Review self study report: } \\
\text { Reports of the internal and external peer review } \\
\text { panels. } \\
\text { Log of Issues : evidence of progress on } \\
\text { objectives and strategies was sought in the } \\
\text { document record. }\end{array}$ \\
\hline Notes & & & $\begin{array}{l}\text { The shorter timeframe for the impact assessment } \\
\text { of PR2 (12 months) needs to be taken into } \\
\text { consideration. }\end{array}$ \\
\hline
\end{tabular}




\begin{tabular}{|l|c|c|c|}
\hline \multicolumn{5}{|c|}{ Table 4 Meeting stated objectives } \\
\hline Threshold & DA1 & PR1 & PR2 \\
\hline$>=33 \%$ & 4 of 4 $(100 \%)$ & 7 of $7(100 \%)$ & 10 of $10(100 \%)$ \\
\hline$>=\mathbf{5 0 \%}$ & 4 of 4 (100\%) & $\mathbf{7 ~ o f ~ 7 ~ ( 1 0 0 \% )}$ & $\mathbf{1 0 ~ o f ~ 1 0 ( 1 0 0 \% )}$ \\
\hline$>=66 \%$ & 4 of 4 $(100 \%)$ & 5 of $7(71 \%)$ & 9 of $10(90 \%)$ \\
\hline
\end{tabular}

\begin{tabular}{|l|c|c|c|}
\hline \multicolumn{4}{|c|}{ Table 5 Peer review panel recommendations } \\
\hline Ref & DA1 & PR1 & PR2 \\
\hline Type & Summative & Formative & Formative \\
\hline Recommendations & 0 & 12 & 13 \\
\hline Completed & n/a & 9 of $12(75 \%)$ & 4 of $13(30 \%)$ \\
\hline
\end{tabular}

\begin{tabular}{|c|c|c|c|}
\hline \multicolumn{4}{|c|}{ Table 5 - Meeting goals and objectives } \\
\hline \multicolumn{1}{|c|}{ Ref } & DA1 & PR1 & PR2 \\
\hline $\begin{array}{l}\text { Stated objectives } \\
\text { and peer review } \\
\text { recommendations }\end{array}$ & 4 & 19 & 23 \\
\hline $\begin{array}{l}\text { Objectives } \\
\text { completed }\end{array}$ & $\mathbf{4}$ of 4(100\%) & $\mathbf{1 6}$ of 19 (84\%) & $\mathbf{1 4}$ of 23 (61\%) \\
\hline
\end{tabular}

\begin{tabular}{|l|c|c|c|}
\hline \multicolumn{4}{|c|}{$\begin{array}{c}\text { Table } 7 \text { Summary of origin of objectives including } \\
\text { peer review recommendations of self study programmes }\end{array}$} \\
\hline & DA1 & PR1 & PR2 \\
\hline Total Objectives & 4 & 19 & 23 \\
\hline $\begin{array}{l}\text { Completed/ongoing objectives } \\
\text { originating within the programme }\end{array}$ & 3 of $4(75 \%)$ & 7 of $19(37 \%)$ & 7 of $23(30 \%)$ \\
\hline
\end{tabular}

